\title{
Towards on E-Multiple Handicapped Information System (EMHAS) Modelling
}

\author{
Hira Laksmiwati and Saiful Akbar \\ School of Electrical Engineering and Informatics, ITB, Indonesia \\ Ganesha 10, Bandung 40132, Indonesia \\ hira@informatika.org, saiful@informatika.org
}

\begin{abstract}
The development of electronic media in the world, such as e-learning, communication through the internet, and information system automation, is growing very fast. While the media is mostly developed for people without disability, a question about how this electronic media being used and utilized by people with disability still remains. People with disability, either mentally or physically, with either single (deaf, blind) or multiple handicapped (mentally deaf, mentally blind) have special needs in order to let them work/utilize this electronic media.

A proposed model of integrating a multiple-handicapped person information management system has been developed [1]. The former focuses on managing all management aspects of rehabilitation, dormitory, school and workshop such that the activity and the improvement of multiple handicapped individual record can be monitored easily.

It emerges some interested point about how this EMHaS Information System being prepare to implement. While these disabled person who have specific characteristics and behaviors became part of the user and they have some difficulties to use the normal electronic devices some preparation activities have taken place. In this paper we discuss on how Enterprise Architecture Planning (EAP) methodology can support the Multiple Handicapped Education Information System development has taken place. Furthermore another study on how Individual Education Program (IEP) in Multiple Handicapped Education Information System can be applied is also explored.

The paper also describe a particular design of man-computer interface for improving disabled persons mental and physical ability. A prototype of handicapped interface device has been designed and implemented in rehabilitation institute Bale Endah, Jawa Barat.

As a case study the education EMHaS model has been developed based on the Indonesia Multiple Handicapped environment which is run by Bhakti Mitra Utama Foundation (BMUF). It is expected that this integrated information system could helps caregivers and managers to manage and monitor disabled persons daily activity in the school and dormitory area more easily and more comprehensively. Another expectation that this result could be count as one system that is really suitable to implement not only in this multiple handicapped foundation (BMUF) but also in all such multipled handicapped foundation or institutes in Indonesia.
\end{abstract}

Keywords: multiple handicapped system, information system, e-disabled devices, Enterprise Architecture Planning (EAP), Individual Education Program (IEP).

\section{Introduction}

Information and Communication Technology (ICT) has grown very rapidly during the last three decades. The ICT enables people to automate their work, to communicate remotely to each other in a very seamless way, to search, collect, and manage useful information/knowledge easily, and so on. Using the ICT people can develop sort of new

Received: April $25^{\text {th }}, 2011$. Accepted: March $6^{\text {th }}, 2012$ 
abilities on their life. While these people get many advantages in the form of developing the new abilities by using the ICT, some people with disabilities still have many questions on how to utilize and take the advantages of the ICT. Many efforts have been done in order to enable them to work or use the ICT. Just to mention a few, several specific devices have been designed and implemented, such as "Breath-JoyStick" [1], tongue-computer interface [6], and the haptic feedback device [7].The above specific devices were designed to let disable persons directly take the advantages of the ICT.

At the same time, in disabled person environment an ICT-based system should be designed to help caregivers, physicians, psychiatrists, and even managers of a rehabilitation institute to manage and monitor the rehabilitation process. The system should manage the biodata of disabled persons, the history of their problems, the diagnoses provided by the physicians or psychiatrists, and also the threatments/trainings facilitated by the caregivers and the progress. This is another way on how the dissable persons may indirectly take the advantages of the ICT. It is hoped that the extension of the Asian and Pacific Decade of Disabled Persons for another 10 years will complete the achievement of the goal of full participation and equality of people with disabilities [4].

Research topic described in this paper actually was proposed with respect to the Asia Pacific Forum (1993) idea on Towards Person with Disabilities in Asia Pacific countries [4]. We highlight the four important points of the declaration to consider [8], i.e. (1) the importance of giving "full support to the improvement of the total well-being of disabled persons and their integration into the mainstream of society", (2) "disabled persons have the same rights as other people", (3) "the rehabilitation of the disabled persons shall be the concern of the Government in order to foster their capacity to attain a more meaningful, productive and satisfying life", and (4) "special education for disabled children is organized specifically for students who suffer from physical, mental and/or behavioral disability". The paper is extended from our previous paper [1]. The extension includes the design of EMHaS School Information architecture based on Enterprise Architecture Planning [11] and implement the prototype of Individual EMHaS System Information which developed based on Individual Education Program [14].

The rest of this paper is organized as follows. Section 2 introduces the living environment of multiple handicapped person as a background where this multiple handicapped information system have been created. Section 3 describes EMHaS logical model as a basic of multiple handicapped information system model. Section 4 discusses more detail about the result of EMHaS school architecture design based on Enterprise Architecture Planning methodology and how the Individual Education Program has been developed in EMHaS. Section 6 describes result study of EMHaS Medical Record System and prototype of multiple handicapped interface devices. Finally, Section 7 presents our conclusions.

\section{The Multiple Handicapped Living Environment}

Bale-Endah Rehabilitation Institute is owned by Bhakti Mitra Utama Foundation (BMUF). The BMUF was established in 1979 and recognised as the first foundation in Indonesia which is taking care and serving disabled person which has more than one disability. The BMUF manages two institutes (1) Bale Endah Institute in Bale Endah, Soreang, Jawa Barat and (2) another institute located in Jambu Dipa Village, Cisarua, Lembang Jawa Barat. In total, the two institutes serve more than fifty (50) multiple handicapped persons (age $12-35$ ). They are living and being educated in the institutes. It is important to notice that the institutes focused on multiple handicapped persons instead of singles ones.

The objectives of BMUF is to assist people who are physically handicapped and mentally retarded to find their place in the community and to be useful in the society.

In Bale Endah Rehabilitation Institute, BMUF open a day-special school for multi handicapped children. In December 1993 The Ministry of Education and Culture of Republic Indonesia formally allocated the name of 'SLB bagian G' (Special School Section G). Now 
this school have 45 multi handicapped children, 10 of which are day school pupils. The rest of them are accommodated in Bale Endah dormitory.

Most of multiple handicapped persons who live in the dormitory are orphans and coming from poor families. For them who finish the school, BMUF serving them with rehabilitation facilities. Caregivers help them lessening their sufferings which is within their reach and help them to earn their own living and try to make them less dependent to other people.

Since 1989, in Jambu Dipa Village, BMUF establish a rehabilitation centre for the grown up multi handicapped person, who classified as a disabled persons who have ability to support their independently live. This Village has prepared a dormitory and working areas where they will be employed in accordance with their remaining and developed skills. This village has sheltered workshop, several kind of handicraft workshop, farming, gardening, fruits and vegetable growing.

\section{EMHAS Logical Model}

The EMHAS logical model aims at describing how the whole aspects of EMHAS related to each other and how the information flow is managed. The model also explains how external systems will interact with the EMHAS System. Thus, the logical model will show the general architecture of the system, and in the same time illustrates the internal system in more detail.

As shown in

Figure 1, according to [1] the logical model of EMHAS consists of six modules. The modules are described as follows.

The registration module serves as a subsystem for registration process of foster children candidates who have multiple handicapped criteria.

The dormitory module is a module that controls every activity of MHPs during their lifetime in the dormitory including social/life skill education, rehabilitation program and daily activity.

The MH school module manages all aspects related to the school activities, including MH learning process, skill development process, and teaching material processing.

The workshop module is responsible for managing workshop-related activities, such as business activities (planting, animal husbandry, ceramic and art) and external communityrelated activities (interaction with people outside the rehabilitation institute).

The rehabilitation module helps the end user to store, observe and monitor all aspects of rehabilitation including physical and non physical condition. Using this module a nurse or a doctor can entry and monitor the MHPs rehabilitation progress and the manager/caregivers can observe the progress.

The reporting module is responsible for generating reports collected from other modules. The report could be generated daily, weekly, monthly, and so on.

It is important to note that a sub modul, i.e. the daily-life activities/education sub module (buble 02.03 in Figure 1) is designed for a specific purpose, i.e for enhancing disabled persons abilities. Using this sub module the caregivers will assign simple MHP tasks to accomplish such as watering plant, cleaning tables, or opening/closing curtains. When an MHP accomplishes the task successfully, she/he deserves to get the reward such as playing a computer game or eating snacks/candies. Hence, the sub module needs to have the reward system. Thus, the sub module is useful for improving their mental and physical abilities. 
Hira Laksmiwati , et al.

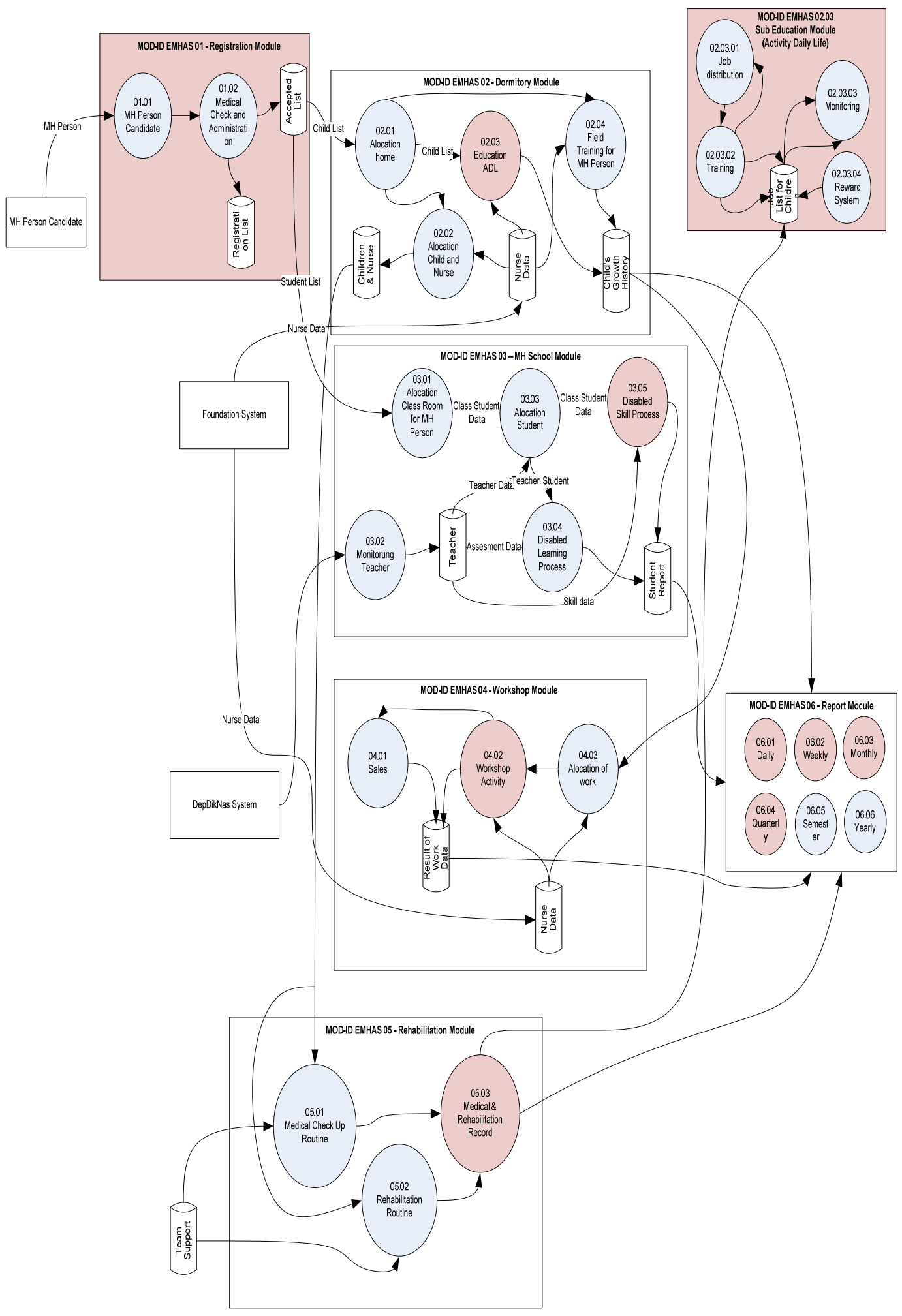

Figure 1. The logical model of EMHAS 
In general, a complete EMHaS should provide the end users with the whole services facilitating aspects of managing, educating, training, and rehabilitating multiple hadicapped persons as shown in Figure 2.

It is noticed that developing the whole system at once will not lead the implementation to a success. The reasons are (1) the Information System expert who is interested to this area are limited (2) the rehabilitation institute has not enough computers, and (3) the organization and operational human resources are not ready to execute a complete and sophisticated system. Therefore, it is decided to explore some parts of the system which are the most important among the others to prepare EMHaS implementation that is EMHaS School System and BEMHaS Medical Record System and Electronic Disabled Communication (EDisCom) devices. While this parts of the system is prepared to be implemented, it is expected that the organization and human resources will gradually learn and adapts with the new EMHaS system environment .

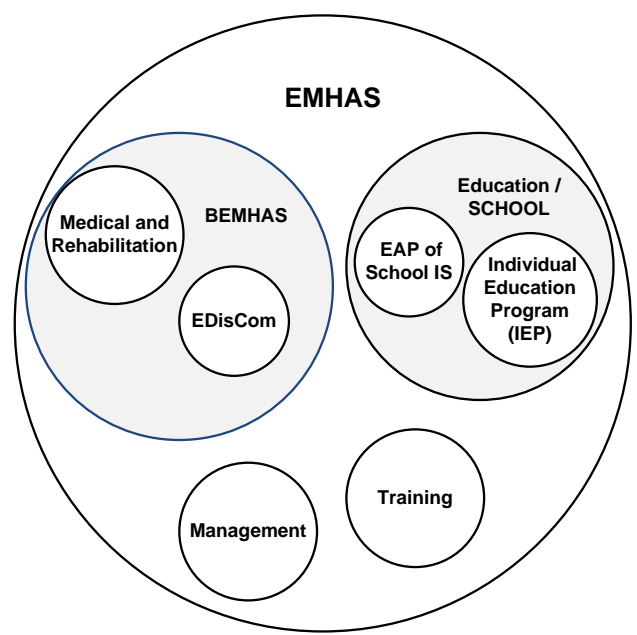

Figure 2. The scope of a complete EMHAS

\section{EMHaS School Information System Preparation using EAP and IEP}

The global architecture of EMHaS School Information System has been designed using Enterprise Architecture Planning (EAP) methodology [12] and the prototype of individual EMHaS Information System is developed using Individual Education Program (IEP) [14] concept. The implementation in detail can be found in [2] and [3]

EAP approach based on Zachman Framework [11] which have four stages of architecture information system building as depicted in Figure 3. The 4 stages are Planning Initiation stage, Current System Business Modeling and Technology stage, Architecture layer stage and Implementation stage.

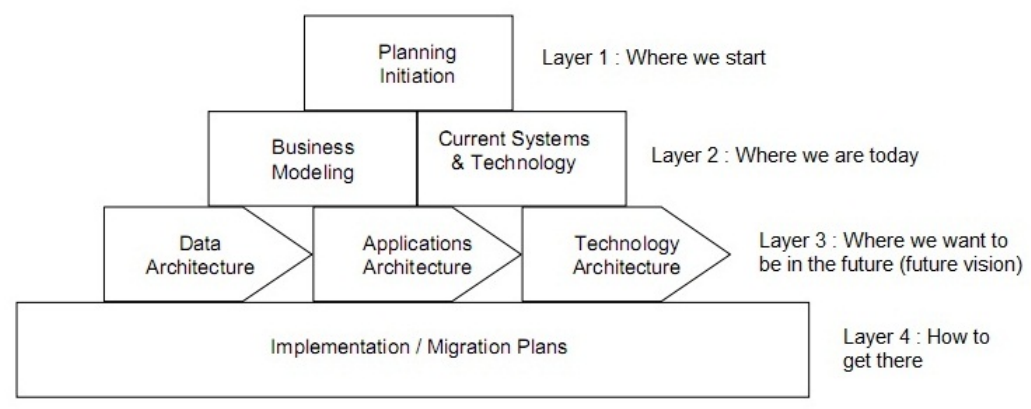

Figure 3. Development Stage of EAP Information System Architecture [12] 
In the architecture layer, the approach deals with data architecture, applications, technology and implementation planning. The process business of the school has been developed with respect to the Indonesia Handicapped School Sekolah Luar Biasa (SLB).

Some functional business area are defined for BEMHaS School including five (5) main business activities and four (4) supporting business activities as shown in Figure 4.

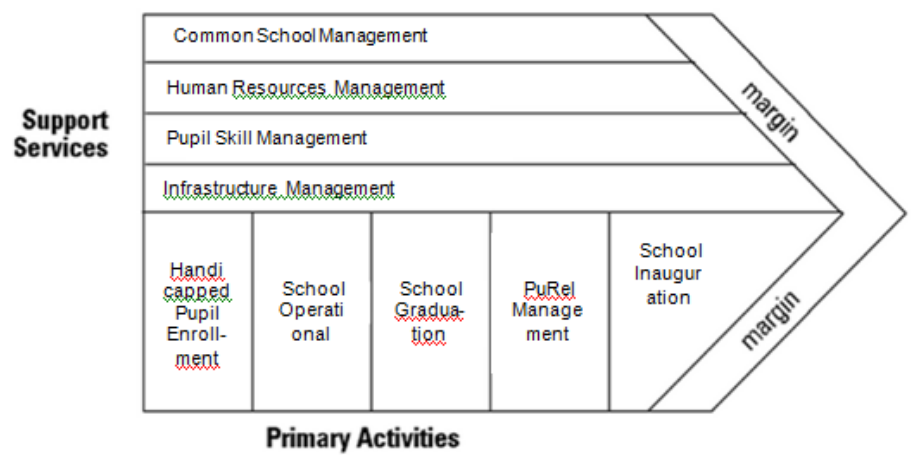

Figure 4. Chain Value Diagram BaleEndah Handicapped School

The nine business area above have been mapped to business processes which refer to existing Bale Endah Handicapped School Business Process, BMUF organization structure and BaleEndah Handicapped School legacy system. The outcome is Business Process Hierarchy Diagram for BaleEndah Handicapped School consisting of 12 organization units and 87 business processes.

As an example, the result of mapping process of one business function that is Handicapped Pupil Enrollment (one of Primary Activities as shown in Figure 4) are several business process. The Handicapped Pupil Enrollment business process hierarchy can be shown in Table 1 below.

Based on EMHaS business process hierarchy the data architecture, application architecture and technology architecture have been designed. The data architecture consists of 62 entities and 6 database subjects. The application architecture produces 12 candidate applications. Technology architecture produces 20 basic principles of technology, 2 conceptual business locations, conceptual workstation, conceptual enterprise networks, as well as the business systems architecture.

Table 1 New Handicapped Enrollment Business Process Hierarchy

\begin{tabular}{|l|l|l|l|}
\hline \multicolumn{2}{|c|}{ Number } & \multicolumn{1}{c|}{ Business Process } \\
\hline 1 & & & New Handicapped Pupil Enrollment \\
\hline & 1 & & New Handicapped Pupil Enrollment Planning \\
\hline & & 1 & Capacity and Standard Determination \\
\hline & & 2 & Handicapped Skill Observation Guide \\
\hline & 2 & & New Handicapped Enrollment Process \\
\hline & & 1 & Candidate Handicapped Pupil Registration \\
\hline & & 2 & Handicapped Skill Pupil Observation \\
\hline & & 3 & Handicapped Pupil Classification \\
\hline & 3 & & New Handicapped Pupil Personal Data Entry \\
\hline
\end{tabular}

During the implementation plan, it is founded that there is a priority sequence on scheduling the application implementation. This schedule will impact to the application migration, technology acquisition, human resources and time estimation. Some aspect of critical success factor has also been identified. These aspect are standard and procedure aspect, 
executive agreement aspect, technology aspect, leadership of implementation aspect, system development methodology aspect, reorganization and training aspect.

Result of the global architecture EMHaS School Information System design and implementation plan has announced and verified by BaleEndah Handicapped School Stakeholder. Some comments to the EMHaS School Information system aroused and correction to this system has been done. Compared to the architecture of common school Information System the EMHaS School Information System architecture has some differences, i.e New Handicapped Pupils Selection, Teaching Program Planning, Examination System, Extracurricular System.

Another approach used in EMHaS School Information System developing is in individual education program [2]. It focuses mainly on how individual handicapped aggregation education (not inclusive education) can be monitored. It is realized that some of the handicapped pupil should be individually handled in the school. They can not learn in a class or group because of lack of communication, lower handicapped grade and should be supervised by special teacher who has special knowledge education of handicapped education.

Figure 5 shows activities contribution on this special education processes of Individuals with Disabilities Education Act (IDEA) [14]. First activity is to observe the handicapped pupil mental and physical condition, then another activity is to find decisions for each handicapped pupil education program. The decision should be agreed between parent, medical team and school staff. Next activity is to write the documentation, and monitor how the education program has been given by the special teacher. Finally an activity to observe the education report should be done to refine continuously handicapped pupil education program.

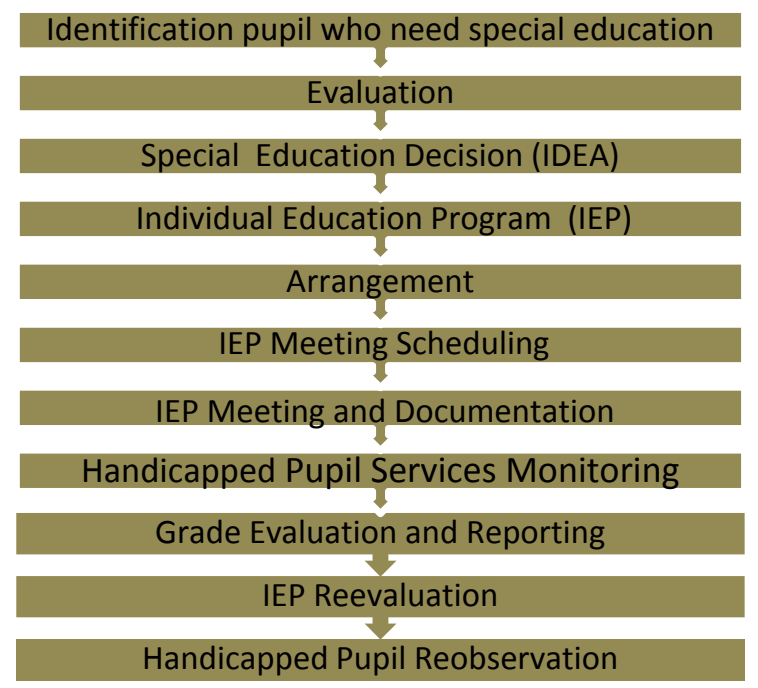

Figure 5. IDEA Special Education [14]

IEP [13] involves two important main point to be noticed, that are :

1. IEP Meeting where handicapped pupil, parent, school staff discuss education program that is suitable for the handicapped pupil

2. IEP documentation in which all decisions of IEP meeting are written.

Survey on BaleEndah Handicapped School gives a handicapped formal education existing schema, handicapped self development and vocational skill. In addition it is founded that a special program is being given for articulation training, character rehabilitation and physiotherapy. 
Several special education processes are being executed in Bale Endah Handicapped School such as handicapped pupil enrollment, handicapped pupil first observation, teaching process using thematic handicapped education, handicapped skill training, handicapped ability improving and handicapped daily rehabilitation.

Based on the survey result in BaleEndah School, the design of EMHaS Individuals Handicapped Education is tailored to be used by Handicapped Pupil in Indonesia. The design cover processes such as handicapped pupil enrollment, handicapped pupil observation, initiation meeting, handicapped individual education planning, handicapped Education Program Implementation, grading and handicapped post education. (Figure 6.)

An application of scenario as shown in Figure 6 - called IEP-G has been developed. There are 15 business process school to be implemented. It is analyzed and designed using UML and run under Web Application using Java EE architecture. Test process [2] shows that all function are running well.

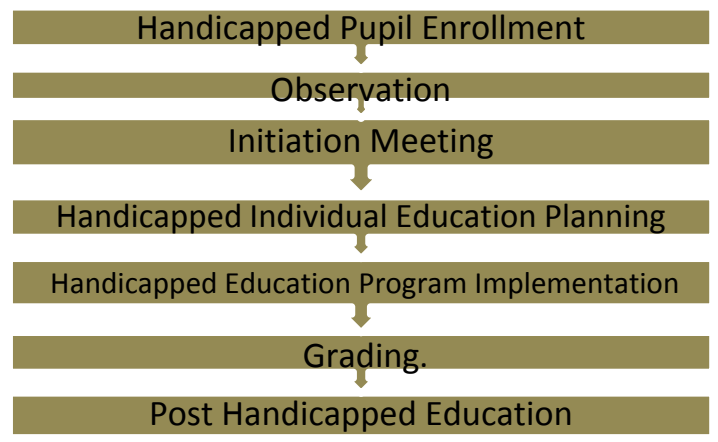

Figure 6. Special Education Stages

for Indonesia Multiple Handicapped School

As a conclusion of this section, both approaches on EAP and IEP show that although the design has been there and some prototype have been proven, some non technical supporting to bring out the complete, integrated handicapped school system is necessary to consider. Challenges on resettled procedures for each education process, efficient organization structure and human resources skill still become a big issue to be solved.

\section{Medical Rehabilitation Module and Electrical Disabled Communication SYstem (EDisCom)}

The former is the implementation of the medical and rehabilitation sub module while the later is the implementation of the daily-life activities/education sub module (see

Figure 1). It is important to note that EDisCom not only manage tasks assigned by cargivers to MHPs but also provide disable persons with a specific device to interact with the computer game system.

According to the discussion with staffs and observation to the multiple handicapped persons in the rehabilitation institute, it is defined that MR-BEMHas (MR-X) should facilitate the caregivers, medical team, psychiatrists, and managers to observe and monitor the medical treatment and rehabilitation process, while EDisCom (ED-X) should facilitate MHP to play with a computer game system. We notice that playing game is not only for fun, but also for improving their mental and physical abilities. The requirements of MR-BEMHas and Ediscom are listed in Table 1.

MR-BEMHaS is implemented in a web environment using PHP and mySQL. A snapshot of a MR-BEMHaS is shown in Figure 7. The main problem of MR-BEMHaS implementation is the availability of the data. Since the rehabilitation institute was used to record all the information manually, it is difficult to find digitized data. The second problem is how to 
change the mind set of caregivers/physicians/doctor from manual data processing into semiautomatic data processing. However, since our implementation focused only in the medical and rehabilitation aspects instead of the whole aspects, it can be done in more clear and focused way.

Table 1. The requirements of (MR-X) and (ED-X)

\begin{tabular}{|l|l|}
\hline Req. ID & Description \\
\hline \hline MR-01 & Managing MHP Personal dan Data \\
\hline MR-02 & Managing medical treatments and rehabilitation \\
\hline MR-03 & $\begin{array}{l}\text { Daily Life-Activity. It facilitate caregivers to } \\
\text { deliver simple tasks for MHp, and record/monitor } \\
\text { how the tasks are accomplished. }\end{array}$ \\
\hline MR-04 & Health reporting \\
\hline ED-01 & $\begin{array}{l}\text { A specific device for interaction with computer } \\
\text { games }\end{array}$ \\
\hline ED-02 & $\begin{array}{l}\text { A computer game system that is appropriate for } \\
\text { MHPs. The system must be operated as simple as } \\
\text { possible. }\end{array}$ \\
\hline $\begin{array}{l}\text { MHP reward system. Bridging MR and ED. MR } \\
\text { records how an MHP performs simple tasks } \\
\text { assigned by the caregiver, and playing game } \\
\text { provided by ED is used as a reward of tasks } \\
\text { completion. }\end{array}$ \\
\hline
\end{tabular}

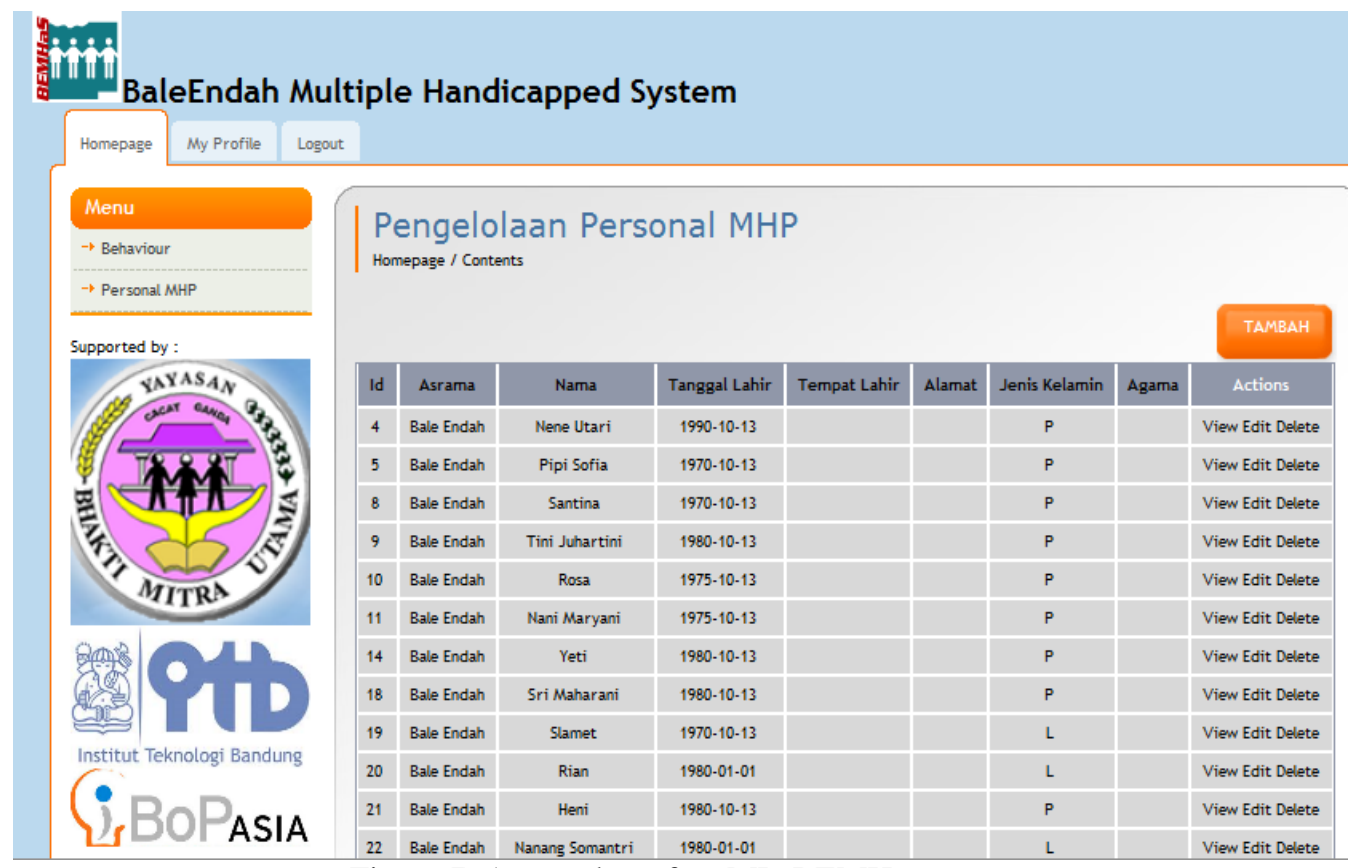

Figure 7. A snapshot of an MR-BEMHas page

It is interesting to observe what kind of device will be suitable for disabled person. It must be as simple as possible, but in the same time provide MHPs with enough input to interact with a simple game system. In this implementation, we focused on developing a simple keyboard. The keyboard should (1) be able to be operated using one hand, one finger, one elbow, or even 
using a tue, (2) consist of a few buttons and the buttons should be big and interesting enough for the MHP, and (3) be easily plugged and played. Considering the three features of the keyboard, we design a simple yet suitable keyboard as shown in Figure 8 and Figure 9. Figure 10 shows how a person with disability in his arm interacts with EDisCom using the simple keyboard.

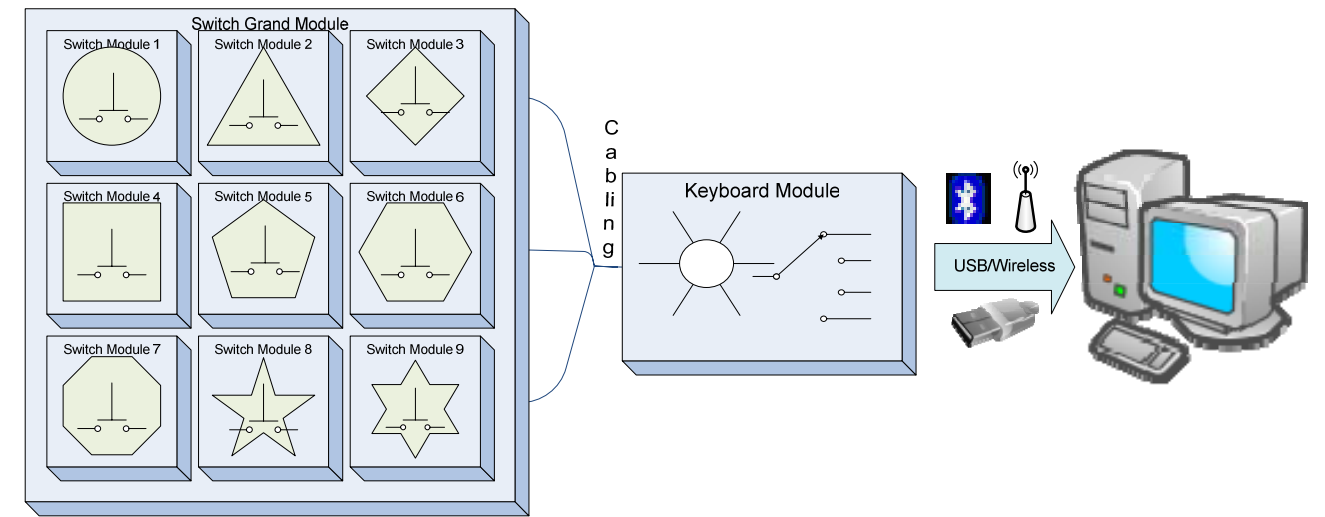

Figure 8 The Logical Design of the EDisCom device

Realizing that MHPs have very limited mental and physical ability to operate a game system, it is important to observed games that are really suitable for them. The games should be able to operated using the simple keyboard. While the MHPs classify as children between 2 to 8 years old then it should be selected toddler games such as painting, playing music, learning alphabets, listening animals voice, etc. In order to enable the games to be operated using the simple keyboard, it is developed a system to map the games' button functionality into the button of the simple keyboard. The mapping can be easily configured for a particular game by editing a configuration text-file dedicated to the game.

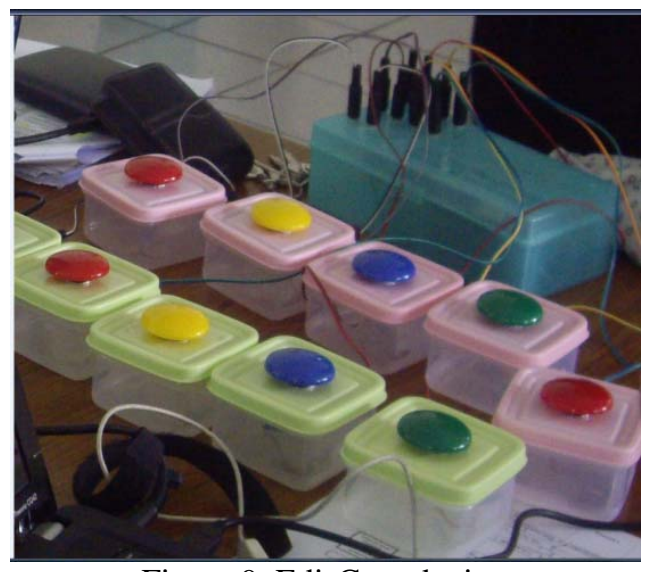

Figure 9. EdisCom device

In order to observe the usability of the system, we interviewed some caregivers and a psychiatrist working in the institute to collect their comments. We highlight that the psychiatrist believes that the system (especially EDisCom) can help the institute to improve either mental or physical ability of MHPs. Moreover, playing simple game using simple keyboard make MHPs being encouraged to reach their mental/physical capacity limit happily. A more systematic observation about the usability needs to be done in the near future to get more accurate and qualitative result. 


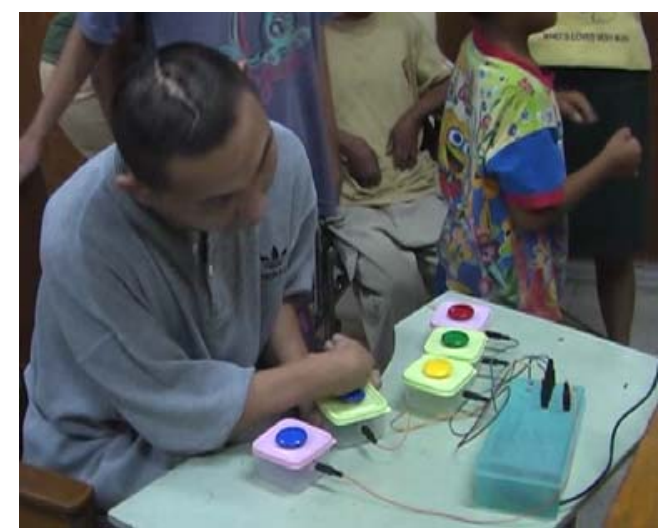

Figure 10. MHP interaction with EDisCom using the specific device

\section{Impact and Conclusions}

EMHaS logical model has been designed as an integrated information system covering all management aspects of rehabilitation, dormitory, school, workshop so the multiple handicapped activity can be monitored. It also concerns with how the daily activity life of MHPs is monitored and maintained.

The use of Bale-Endah-EMHaS (BEMHaS) can influence the social worker and teacher on how they are prepare the frequently report. Each school, dormitory, rehabilitation and workshop data that will store in the server can be access anytime they need. It will support more accuracy, more complete in ordering multiple handicapped data.

Two big sub systems are ready to implement, the multiple handicapped school sub system and the activity daily live (ADL) sub system. From the point of view of management and controlling teaching procedures, rehabilitation procedures and ADL procedures BEMHaS can show an automation procedures under electronics environment.

One interest thing to be noticed that the psychologist find that the Game Reward System can be used to stimulate the MHP Focus Level Improvement. Up to now the psychologist can not find a methodology for that condition.

\section{Ackonowledgements}

We are very grateful to the numerous students who contribute in this research and build some implementations details. We thanks to Huda Ubaya who implemented EdisCom device and Fivien Savitri and Novi Setiani who developed the application for the case study. We also thanks to Eka Mukti Arifah and Andara Livia who used IEP and EAP respectively to observe in detail and implements the EMHaS School Information System.

\section{References}

[1] Hira Laksmiwati, Saiful Akbar, Fivien Savitri, Huda Ubaya, "E-Multipled Handicapped System (EMHaS) Modelling” 2011 ICEEI Conference, Bandung, July 2011

[2] Eka Mukti Arifah, "Pembangunan Sistem Pengelolaan Individual Education Program (IEP) bagi Penyandang Cacat Ganda di Indonesia”, Informatics Study Program, STEI ITB. October 2011

[3] Andara Livia, "Perancangan Arsitektur Sistem Informasi dengan Enterprise Aechitecture Planning untuk Sekolah Luar Biasa tipe G”, Informatics Study Program, STEI ITB, October 2011

[4] Highlights of the Asian and Pacific Decade of Disabled Persons,1993-2002 Social Policy Paper No. 13 Economic and Social Commision for Asia and the Pacific, United Nations Publication, Sales No. E.04.II.F.7, Copyright (C) United Nations 2003, ISBN: 92-1120360-0 
[5] Evreinov Grigori, Evreinova Tatiana. "Breath-Joystick" - Graphical Manipulator for Physically Disabled Users. Computer Helping People with Special Needs. ICCHP2000,. Proceedings of the 7th International Conference on Computer Helping People with Special Needs. . july 17-21, 2000, Karlsruhe, Germany. - p.p. 193-200

[6] A. Struijk, Tongue-computer interface for disabled people, In. Proc. of 6th Int. Conference on Disability, Virtual Reality and Associate Technologies, 2006

[7] Tapson, J.; Gurari, N.; Diaz, J.; Chicca, E.; Sander, D.; Pouliquen, P.; EtienneCummings, R.; In Proceedings of Biomedical Circuits and Systems Conference, 2008. BioCAS 2008. 20-22 Nov. 2008. pp. 381 - 384

[8] Report on the international workshop for national human right institutions from the commonwealth and asia pacific region, "Promoting the rights of People with Disabilities Towards a New United Nations Convention”, Asia Pacific Forum of National Human Rights Institutions, India 2003

[9] Simkiss, Philippa, Floyd, Michael; Developing a computerized information system for visually disabled people to assist with job placement, International Journal of Rehabilitation Research: Volume 18 - Issue 2 June 1995.

[10] Marjuki, Dr., M.Sc. Penyandang Cacat - Berdasarkan Klasifikasi International Classification of Functioning for Disability and Helath (ICF). Departemen Sosial Republik Indonesia. 2010.

[11] Zachman, John A. Excerpts from The Zachman Framework for Enterprise Architecture: Primer for Enterprise Engineering and Manufacturing. Zachman International. 2003.

[12] Spewak, S. H. Developing Blueprint for Data, Applications, and Technology: Enterprise Architecture Planning. John Wiley \& Sons. 1992.

[13] Rebhorn, T. (2009). Developing Your Child's IEP. NICHCY National Dissemination Center for Children with Disabilities.

[14] Price-Ellingstad, D. et al., (2000). A Guide to the Individualized Education Program. Editorial Publications Center U.S. Department of Education.

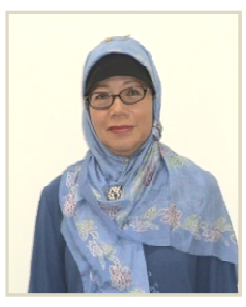

Hira Laksmiwati Z. is an associate professor in the School of Electrical Engineering and Informatics, Institute of Technology Bandung. She is the head of Data \& Software Engineering Research Division. Her research interests include object oriented database, metadata development, system and software development. She is a member of the ACM computer Society. Contact her at hira@informatika.org

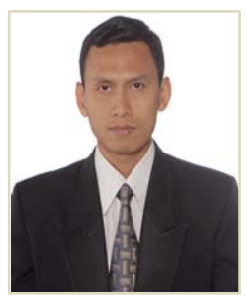

Saiful Akbar is an assistant professor in the School of Electrical Engineering and Informatics. He received a PhD in Engineering Science from the University of Linz Austria. His research interests include multimedia similarity retrieval, information extraction, and application framework. He is a member of the IEEE computer society. Contact him at saiful@informatika.org 